\title{
Effects on Patient Care Caused by Drug Shortages: A Survey
}

\author{
Milena McLaughlin, PharmD, MSc, BCPS, AAHIVP; Despina Kotis, PharmD, FASHP; \\ Kenneth Thomson, BS, MBA; Michael Harrison, BS; Gary Fennessy, BS, MBA; \\ Michael Postelnick, BS, BCPS AQ-ID; and Marc H. Scheetz, PharmD, MSc, BCPS AQ-ID
}

\begin{abstract}
BACKGROUND: Drug shortages pose a serious challenge for health care institutions, often interfering with patient care. A common practice during a drug shortage is to select an alternate therapeutic; however, these agents often present challenges and may create safety concerns. Patient harms including adverse events and medication errors may occur. Patients may also file complaints because of drug shortages.
\end{abstract}

OBJECTIVE: To measure the effect of drug shortages on patient outcomes, clinical pharmacy operations, patient complaints, and institutional cost.

METHODS: An e-mail link to an online survey was sent to pharmacy director members in the MedAssets Pharmacy Group Purchasing Organization. Data were collected within a 3-week period from 0ctober 2-23, 2012. The survey focused on 6 different domains: demographics, adverse events, medication errors, patient outcomes, patient complaints, and institutional cost.

RESULTS: The survey was sent to 1,516 directors of pharmacy. There were 193 respondents (response rate 13\%) who participated in the survey. Approximately $40 \%$ of respondents reported between 1 and 5 adverse events probably or possibly associated with drug shortages at their institution. The majority of respondents reported between 1 and 10 medication errors. The most common types of medication errors reported were omission $(n=86,55.5 \%)$, wrong dose dispensed/administered $(n=85,54.8 \%)$, and wrong drug dispensed/administered $(n=54,34.8 \%)$. The most common outcomes reported by respondents were alternative medication used $(n=146,85.3 \%)$, delay of therapy $(n=121,70.8 \%)$, and increased patient monitoring necessary $(n=84,49.1 \%)$. Patient complaints were reported by $38 \%$ of respondents. The majority of respondents reported an estimated quarterly institutional cost from shortages of less than $\$ 100,000$, and approximately one quarter of respondents reported adding at least 1 full-time equivalent to manage drug shortages. The majority of participant comments mentioned the increasing institutional costs attributed to drug shortages.

CONCLUSIONS: Medication errors and adverse events continue to occur from drug shortages, often resulting in inadequate patient care, high institutional costs, and patient complaints. Delayed care and cancelled care have been reported from shortages. Further research is necessary to better classify medication errors and adverse events during a drug shortage.

J Manag Care Pharm. 2013;19(9):783-88

Copyright $\odot 2013$, Academy of Managed Care Pharmacy. All rights reserved.

\section{What is already known about this subject}

- Drug shortages have been increasing since the early 2000s. They create barriers to safe and effective medication therapy on a daily basis. Even when alternate medications are procured, there are unintended consequences, including adverse events and medication errors associated with the alternative therapy.
- Research to date has elucidated several reasons for drug shortages that include manufacturing issues, regulatory infractions, voluntary recalls, business decisions, and natural disasters (U.S. GAO, 2011; Fox and Tyler, 2003). There are national efforts to prospectively monitor drug shortages and increase the number of early notifications to allow the U.S. Food and Drug Administration an appropriate amount of time to work with manufacturers to avoid shortages.

\section{What this study adds}

- The survey results describe the ongoing effects of drug shortages on patient care, pharmacy operations, and patient harm caused by drug shortages. Details are provided regarding the number and types of cancelled care or delayed therapies. Our results also indicate that resources are being allocated and/or diverted from patient care responsibilities to the management of drug shortages.

- The current survey is the first to our knowledge to describe the effects of drug shortages on patient complaints. The effects of such shortages on patient complaints may have future implications for health care reimbursement.

$\square$ ver the last several years, drug shortages have posed a serious challenge for health care institutions to provide consistent, effective, and safe patient care. A common practice during a drug shortage is to select an alternate agent to continue patient care without disruption. While many institutions require approval for therapeutic alternatives through the Pharmacy and Therapeutics Committee, these alternate agents often present challenges and may create safety concerns.

Unintended consequences of using alternate agents during a drug shortage include adverse events and medication errors. ${ }^{1}$ Previous surveys suggest that institutions across the United States are experiencing patient harms that are attributable to drug shortages. ${ }^{1-4}$ In 1 survey, almost two thirds of pharmacy director respondents believed that drug shortages have changed patient care. ${ }^{3}$ These patient harms included medication errors or near misses, adverse events, cancelled care, and delayed care. In some cases, alternate medications may not exist and may lead to poor patient outcomes. ${ }^{1,5,6}$ Beyond direct patient harm, shortages may also have an effect on the drug budget of the institution. Furthermore, clinicians may need to spend time away from patient care duties, procuring medication and ensuring proper education regarding alternate agents. ${ }^{4}$ 
The trends and causes as well as specific reports of patient harm caused by shortages have been documented. ${ }^{7}$ To our knowledge, the effects of drug shortages on patient complaints have not been well documented in the literature. The purpose of our survey was to quantify the effect of drug shortages on patient outcomes, clinical pharmacy operations, patient complaints, and institutional cost. The goal of our study was to fill informational gaps from previous surveys as well as to gather contemporary data regarding these patient care issues.

\section{Methods}

An online survey was developed using Cvent (McLean, VA) to focus on patient outcomes caused by national drug shortages. The survey was piloted by the MedAssets Pharmacy Coalition to review the clarity of questions. The MedAssets Pharmacy Coalition is composed of individuals from several health care areas, including acute care, nonacute care, management, and industry. An e-mail was then sent to pharmacy directors in the MedAssets Pharmacy Group Purchasing Organization membership with a link inviting them to participate in the survey. The survey launched on October 2, 2012, and concluded on October 23, 2012, with 3 e-mails sent to encourage participation. No personal or institutional identifying information was collected, and respondents had the option of not responding to questions. This study was approved as exempt by the Northwestern University and Midwestern University institutional review boards.

The survey focused on 6 different domains: demographics, adverse events, medication errors, patient outcomes, patient complaints, and institutional cost. Survey respondents were asked to think about the question in the context of the last 2 years prior to the survey. All questions were multiple choice or multiple answer.

\section{Demographics}

Demographic questions included type of institution, location of institution, number of patients served, and the drug category of medications that were unavailable.

\section{Adverse Events}

Adverse events that were possibly or probably related to a drug shortage as determined by the participant were tabulated. Adverse events were categorized according to the National Cancer Institute Guidelines for Investigators: Adverse Event Reporting Requirements. ${ }^{8-10}$ "Possibly related" was defined as a case in which the adverse event may be related to the drug shortage, and "probably related" was defined as a case in which the adverse event is likely related to the shortage. ${ }^{10}$ Total adverse events resulting in death, permanent harm, and requiring intervention were also listed.

\section{Medication Errors}

A medication error was defined as "any error occurring in the medication use process." 11 Total medication errors were tabulated as well as the types of medication errors (wrong drug dispensed/administered, wrong dose dispensed/administered, wrong administration route, wrong frequency, wrong indication, omission, and other). Respondents were also asked about the number of category G-I events at their institutions caused by shortages (categories defined by the National Coordinating Council for Medication Error Reporting and Prevention). ${ }^{8,9,12}$ A category $G$ event was defined as an error that likely caused permanent harm; a category $\mathrm{H}$ event was defined as an error requiring intervention to sustain life; and a category I event was defined as an error that likely contributed to patient death. ${ }^{12}$

\section{Patient Outcomes}

Information was solicited regarding drug shortages and delays of care or cancellations of care and the total numbers of each of these events. Type of cancelled care was also tabulated. Delayed care was defined as any treatment that could not be provided when it was required. Cancelled care was defined as any treatment that was abandoned or terminated because of a drug being unavailable. Other patient outcomes included death, treatment failure, readmission due to treatment failure, increased length of hospitalization, increased patient monitoring, patient transferral to an institution with a supply of the needed medication, delay of therapy, suboptimal treatment, and use of alternative medications.

\section{Patient Complaints}

Respondents were asked if their institutions had received any patient complaints caused by drug shortages and the number of complaints. Respondents were also asked if patients were providing their own medications to the hospital because of a drug shortage.

\section{Institutional Cost}

Respondents were asked if they were estimating their costs related to shortages and the approximate cost of shortages to their institutions. The number of full-time equivalent (FTE) positions that were added to the institution to manage drug shortages was also recorded.

\section{Participant Comments}

Respondents were invited to summarize the effect of drug shortages on their institutions in their own words. Comments were categorized into 5 different domains: medication error, adverse event, patient outcome, patient complaints, and institutional cost to quantify the number of comments in each domain. Each comment could be categorized into more than 1 domain. Comments were assessed for content only, and any 


\begin{tabular}{|c|c|c|}
\hline Characteristic & & $\begin{array}{l}\text { ndents } \\
193) \\
\%)\end{array}$ \\
\hline \multicolumn{3}{|l|}{ Institution type } \\
\hline Acute care hospital & 163 & $(84.5)$ \\
\hline Home health care & 5 & $(2.5)$ \\
\hline Long-term care (closed pharmacy) & 3 & (1.6) \\
\hline Ambulatory care centers & 1 & $(0.52)$ \\
\hline Surgery centers & 1 & $(0.52)$ \\
\hline Correctional providers & 1 & $(0.52)$ \\
\hline Oncology facility/cancer treatment center & 1 & $(0.52)$ \\
\hline Managed care plan & 1 & $(0.52)$ \\
\hline Other & 17 & $(8.8)$ \\
\hline \multicolumn{3}{|l|}{ Institution location } \\
\hline Urban & 64 & (33) \\
\hline Suburban & 65 & (34) \\
\hline Rural & 63 & (33) \\
\hline \multicolumn{3}{|l|}{ Number of inpatient beds } \\
\hline$<100$ & 76 & (39) \\
\hline 100 to 249 & 58 & (30) \\
\hline 250 to 499 & 37 & (19) \\
\hline 500 to 749 & 8 & (4) \\
\hline 750 or more & 9 & (5) \\
\hline Not applicable & 5 & (3) \\
\hline
\end{tabular}

individual events reported in the comments were not included in the previous survey questions to avoid duplicative reporting of results.

\section{Statistical Analyses}

Descriptive statistics were compiled for demographics, adverse events, medication errors, patient outcomes, patient complaints, institutional cost, and participant comment categories. Data were analyzed using Microsoft Office Excel 2010 (Microsoft, Redmond, WA).

\section{Results}

The survey was sent to 1,516 directors of pharmacy in the MedAssets membership database. In total, 204 participants responded with 193 respondents (response rate 13\%) agreeing to take the survey. The majority of the respondents were from acute care institutions that serve less than 100 patients, and the location of the respondents was divided evenly among suburban, urban, and rural institutions (Table 1). The 3 most common categories of medications that respondents reported as unavailable were analgesics/anesthetics $(n=176,91.7 \%)$, anti-emetics $(n=171,89 \%)$, and electrolytes/total parenteral nutrition ( $\mathrm{n}=162,84.4 \%)$.

\section{Adverse Events}

Of 174 respondents, $42 \%(n=73)$ reported no possible or probable adverse events from drug shortages (Table 2). There

\section{TABLE 2 Adverse Events Caused by} Drug Shortages

\begin{tabular}{l|rr}
\hline Adverse Event/Relation & \multicolumn{2}{|c}{ Respondents (n, \%) } \\
\hline Adverse event possibly/probably related to a drug shortage $(\mathbf{n}=\mathbf{1 7 4})$ \\
\hline 0 & 73 & $(42)$ \\
\hline 1 to 5 & 72 & $(41.4)$ \\
\hline 6 to 10 & 16 & $(9.2)$ \\
\hline 10 to 15 & 7 & $(4)$ \\
\hline$>15$ & 6 & $(3.4)$ \\
\hline Patient death caused by a drug shortage $(\mathbf{n}=\mathbf{1 7 9 )}$ & & \\
\hline 0 & 177 & $(98.9)$ \\
\hline 1 to 5 & 2 & $(1.1)$ \\
\hline 6 to 10 & 0 & $(0)$ \\
\hline 10 to 15 & 0 & $(0)$ \\
\hline$>15$ & 0 & $(0)$ \\
\hline
\end{tabular}

Disabling event caused by a drug shortage $(n=179)$

\begin{tabular}{l|rr}
\hline 0 & 176 & $(98.3)$ \\
\hline 1 to 5 & 3 & $(1.7)$ \\
\hline 6 to 10 & 0 & $(0)$ \\
\hline 10 to 15 & 0 & $(0)$ \\
\hline$>15$ & 0 & $(0)$ \\
\hline
\end{tabular}

Event requiring intervention caused by a drug shortage $(\mathrm{n}=179)$

\begin{tabular}{l|rr}
\hline 0 & 133 & $(74.3)$ \\
\hline 1 to 5 & 34 & $(19)$ \\
\hline 6 to 10 & 7 & $(3.9)$ \\
\hline 10 to 15 & 0 & $(0)$ \\
\hline$>15$ & 5 & $(2.8)$ \\
\hline
\end{tabular}

were $41.4 \%(n=72)$ of respondents reporting 1 to 5 possible or probable adverse events, and $3.4 \%(n=6)$ reported greater than 15 of these events. Of 179 respondents, 2 (1.1\%) noted 1 to 5 patient deaths from drug shortages; $3(1.7 \%)$ reported a disabling adverse event in 1 to 5 patients; and 34 respondents (19\%) noted adverse events requiring intervention in 1 to 5 patients.

\section{Medication Errors}

Of 183 respondents, 53\% ( $\mathrm{n}=97)$ reported 1 to 10 medication errors, and $2.2 \%(n=4)$ reported greater than 30 medication errors caused by drug shortages. Serious errors were reported by 5 respondents (2.8\%), with 1 to 5 category G (likely caused permanent harm); 9 respondents (5\%), with 1 to 5 category $\mathrm{H}$ (required intervention to sustain life); and 2 respondents (1.1\%), with 1 to 5 category I (likely contributed to patient death). The most common types of medication errors reported were omission ( $n=86,55.5 \%$ ), wrong dose dispensed/administered $(n=85,54.8 \%)$, and wrong drug dispensed/administered $(n=54,34.8 \%$, Figure 1).

\section{Patient Outcomes}

There were 134 respondents reporting delayed care, while 64 respondents reported cancelled care. Of the 134 respondents reporting any delayed care event, 131 reported the number of 


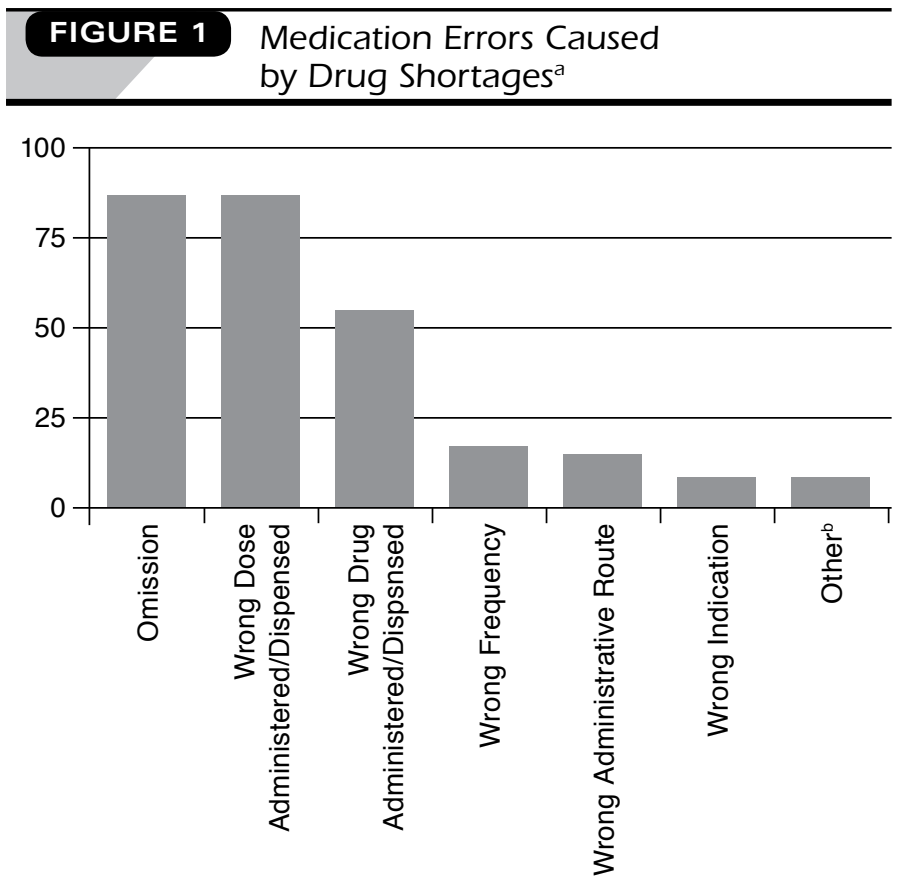

$a_{N}=236$ individual reports, 155 respondents.

b"Other" category included possible incorrect dosage, inappropriate monitoring, delay in treatment because of lack of knowledge, incorrect substitution, not a preservative-free product, delay in administration, delay in therapy, drug-drug interaction ( $n=1$ for each report).

delayed care events, with 74 (56.5\%) noting 1 to 5 delays of care and 29 (22.1\%) noting 6 to 10 delays of care. Greater than 10 delays of care were reported by 28 respondents (21.4\%). Of the 64 respondents reporting cancelled care, 60 reported the number of delayed care events, with 53 respondents (88.3\%) reporting 1 to 10 cancellations of care. These cancellations included procedures (39.6\%), surgeries (21.9\%), chemotherapy (30.2\%), and other treatments (8.3\%). The most common outcomes reported by respondents were alternative medication used $(n=146,85.3 \%)$, delay of therapy $(n=121,70.8 \%)$, and increased patient monitoring necessary $(n=84,49.1 \%$, Table 3$)$. There were 15 reports of readmission due to treatment failure.

\section{Patient Complaints}

Of 190 respondents, 72 (38\%) reported at least 1 patient complaint because of drug shortages, with 66 respondents reporting the number of complaints received. Report of 1 to 5 patient complaints came from 43 respondents (65\%), and 12 respondents (18\%) reported greater than 10 patient complaints. Overall, $9 \%$ of respondents $(n=16)$ reported that patients provided their own supply of a medication that was in shortage. These medications included metoclopramide $(n=1)$, methotrexate $(n=1)$, and bumetanide $(n=1)$. The other 13

\section{TABLE 3 Patient Outcomes Caused} by Drug Shortages

\begin{tabular}{|c|c|c|}
\hline \multirow{2}{*}{$\begin{array}{l}\text { Patient Outcome } \\
\text { Alternative medication used }\end{array}$} & \multicolumn{2}{|c|}{$\begin{array}{c}\text { Reports } \\
(\mathrm{N}=542 \text { Individual Reports } \\
171 \text { Respondents }) \\
(\mathrm{n}, \%)\end{array}$} \\
\hline & 146 & $(85.3)$ \\
\hline Delay of therapy & 121 & $(70.8)$ \\
\hline Increased patient monitoring necessary & 84 & $(49.1)$ \\
\hline Suboptimal treatment & 83 & $(48.5)$ \\
\hline Increased length of hospitalization & 56 & $(32.7)$ \\
\hline Treatment failure & 27 & $(15.8)$ \\
\hline $\begin{array}{l}\text { Patient transferred to an institution with a } \\
\text { supply of the needed medication }\end{array}$ & 21 & $(12.3)$ \\
\hline Re-admission caused by treatment failure & 15 & $(8.8)$ \\
\hline Death & 2 & $(1.2)$ \\
\hline
\end{tabular}

respondents could not recall the exact medication that was provided by the patient.

\section{Institutional Cost}

Of 187 respondents, 51 (27\%) reported that they are estimating their quarterly institutional costs from drug shortages. From these respondents, 50 gave numbers on their estimated costs, with 37 (73\%) calculating costs from drug shortages of greater than $\$ 100,000$, and $13(26 \%)$ estimating costs from drug shortages of less than $\$ 100,000$. Of 184 respondents, 49 (26.6\%) reported adding 0.6 to 1 FTEs because of drug shortages to sustain the increased workload (Table 4).

\section{Participant Comments}

A total of 123 respondents provided comments regarding the effect of drug shortages on their institution. Of these comments $74 \%$ were related to institutional cost (including the cost of procuring medications and the number of FTEs dedicated to managing shortages), $24 \%$ to patient outcomes, $11 \%$ to medication errors, and $8 \%$ to adverse events. Respondents in $4 \%$ of the comments noted that they believed shortages were resulting in patient complaints.

\section{Discussion}

Nearly half of respondents in this survey reported adverse events occurring from drug shortages. Medication errors were most frequently associated with omission, wrong dose dispensed/administered, and wrong drug dispensed/administered. Procedures, surgeries, and chemotherapy treatments were cancelled because of drug shortages by approximately two thirds of respondents. Respondents also needed to increase the number of FTEs dedicated to shortage management. This survey demonstrates that institutions are experiencing medication errors and adverse effects including patient deaths 


\begin{tabular}{|c|c|c|}
\hline umber of FTEs & & $\begin{array}{l}\text { ndents } \\
184) \\
\%)\end{array}$ \\
\hline to 0.5 & 115 & $(62.5)$ \\
\hline 6 to 1 & 49 & (26.6) \\
\hline \multirow[t]{3}{*}{5 to 2} & 16 & $(8.7)$ \\
\hline & 1 & $(0.55)$ \\
\hline & 1 & $(0.55)$ \\
\hline 3 & 2 & (1.1) \\
\hline
\end{tabular}

FTE $=$ full-time equivalent.

caused by drug shortages, despite attempted warnings from national organizations of the unintended consequences of drug shortages. ${ }^{1}$

Our survey additionally revealed that patient complaints are being received because of drug shortages and that there have been readmissions for treatment failure caused by drug shortages. Health care institutions should consider the potential effects of shortages on Hospital Consumer Assessment of Healthcare Providers and Systems scores, specifically patient satisfaction with the institution. ${ }^{13}$ Decreased patient satisfaction and increased readmissions caused by shortages may have a future effect on finances.

Drug shortages have been increasing since the early 2000s, and several surveys have been conducted regarding the effects of these shortages. ${ }^{2,3}$ In 2004, Baumer et al. sought to assess the effect of drug shortages on patient care by conducting an analysis of survey responses from 370 pharmacy directors. During this time frame, $4 \%$ of respondents $(n=15)$ reported a serious adverse drug reaction. ${ }^{3}$ In our study, 3 respondents reported 1 to 5 disabling events caused by a shortage; 34 respondents reported 1 to 5 events requiring intervention from a shortage; and 2 respondents reported 1 to 5 patient deaths caused by a shortage. In just a few years, the raw number of adverse reaction reports has increased. A drug shortage survey conducted in 2010 by the Institute for Safe Medication Practices of 1,800 health care professionals revealed that more than half of the respondents reported encountering several issues, including lack of information and warning, financial effects, re-allocation of resources to manage shortages, risk of adverse events, and physician anger towards the pharmacy. ${ }^{1}$ Of special concern is the fact that many of these issues were reported with high-alert medications, including propofol, heparin, morphine, and chemotherapeutic agents.

Kaakeh et al. (2011) conducted a survey of pharmacy directors and analyzed results from 353 respondents. ${ }^{4}$ The authors reported that few institutions had added FTEs for shortage management. The median number of positions added was 0.1
FTE and 0.5 FTE for pharmacists and pharmacy technicians, respectively. Similarly, only $2 \%$ of respondents in the Baumer et al. survey indicated adding pharmacist positions focused significantly on shortage management. ${ }^{3}$ Our survey, by contrast, indicated that a majority of respondents are dedicating more resources to shortage management. The main cause of increased costs reported in the Baumer et al. survey was attributed by the respondents to purchasing the same product at higher prices. ${ }^{3}$ These results were consistent with the large number of respondents in our survey who commented on cost, indicating that they were buying the same product from a different source at a higher price.

In 2011, the American Hospital Association (AHA) surveyed 820 community hospitals regarding drug shortages. ${ }^{2}$ The AHA noted that $82 \%$ of hospitals had delayed treatment because of a shortage, or they had been forced to use second-line agents. There were also reports from 32\% noting an adverse outcome "frequently or always" from drug shortages. In addition, the survey reported that the majority of hospitals had experienced increased drug costs, most commonly because of the need to purchase more costly alternative medication from alternate sources, ${ }^{2}$ consistent with findings from our survey.

\section{Limitations}

The results from our survey were driven by respondents from acute care institutions; however, based on other survey results, clearly all sizes and types of hospitals are affected by shortages. ${ }^{1-4}$ Our survey also had an attenuated response rate, likely demonstrating a selection bias toward event reporting, but documentation of events was the desired goal, and the absolute numbers reported are still considerable. Reporting rates may have been low as respondents may not have disclosed medication errors or adverse events that occurred at their organizations. Thus, the number of occurrences of these events is likely under-reported, as has been noted in previous studies. ${ }^{14}$ Despite these limitations, the results of this survey provide valuable ongoing information regarding harms because of drug shortages.

\section{Conclusions}

Drug shortages continue to be a burden on health care resources. Medication errors and adverse events continue to occur because of drug shortages, and an increasing number of health care resources are being dedicated to shortage management. Delayed care and cancelled care have been reported as well as patient complaints because of drug shortages. Further research is necessary to determine proper management strategies for reducing medication errors and adverse events during a drug shortage. 


\section{Authors}

MILENA MCLAUGHLIN, PharmD, MSc, BCPS, AAHIVP, is Assistant Professor of Pharmacy Practice, and MARC H. SCHEETZ, PharmD, MSc, BCPS AQ-ID, is Associate Professor of Pharmacy Practice, Midwestern University Chicago College of Pharmacy, Chicago, Illinois. DESPINA KOTIS, PharmD, FASHP, is Director of Pharmacy, and MICHAEL POSTELNICK, BS, BCPS AQ-ID, is Senior Infectious Diseases Pharmacist and Clinical Practice Manager, Northwestern Memorial Hospital, Chicago, Illinois. KENNETH THOMSON, BS, MBA, is Senior Vice President, Lean Operations, and MICHAEL HARRISON, BS, is Manager, LEAN/PMO Operations, MedAssets, Alpharetta, Georgia. GARY FENNESSY, BS, MBA, is Vice President, Operations, Northwestern HealthCare, Chicago, Illinois.

AUTHOR CORRESPONDENCE: Milena McLaughlin, PharmD, Midwestern University Chicago College of Pharmacy, Department of Pharmacy Practice, 555 31st St., Downers Grove, IL, 60515. Tel.: 630.515.7293; Fax: 630.515.6958; E-mail: milgriff@nmh.org.

\section{DISCLOSURES}

Thomson and Harrison are employees of MedAssets, Inc., which helped to develop the survey. McLaughlin has received payment from MedAssets for webinar and business summit presentations. The other authors report no disclosures.

Study concept and design were contributed primarily by Fennessy, Kotis, and Thomson, with input from the other authors. Data collection was primarily done by Thomson and Harrison, and all authors participated in data interpretation. The manuscript was primarily written by McLaughlin, with input from Scheetz, and revision was primarily done by Kotis and Postelnick, with input from the other authors.

\section{ACKNOWLEDGMENTS}

The authors would like to acknowledge the MedAssets Pharmacy Coalition for its assistance with developing and piloting the survey.

\section{REFERENCES}

1. Institute for Safe Medication Practices. Drug shortages: national survey reveals high level of frustration, low level of safety. ISMP Medication Safety Alert: Acute Care Edition. 2010;15:4.

2. American Hospital Association. AHA survey on drug shortages. July 12, 2011. Available at: http://www.aha.org/content/11/drugshortagesurvey.pdf. Accessed July 19, 2013.

3. Baumer AM, Clark AM, Witmer DR, Geize SB, Vermeulen LC, Deffenbaugh JH. National survey of the impact of drug shortages in acute care hospitals. Am J Health Syst Pharm. 2004;61(19):2015-22.

4. Kaakeh R, Sweet BV, Reilly C, et al. Impact of drug shortages on U.S. health systems. Am J Health Syst Pharm. 2011;68(19):1811-19.

5. Ralls MW, Blackwood RA, Arnold MA, Partipilo ML, Dimond J, Teitelbaum DH. Drug shortage-associated increase in catheter-related blood stream infection in children. Pediatrics. 2012;130(5):e1369-73.

6. Metzger ML, Billett A, Link MP. The impact of drug shortages on children with cancer-the example of mechlorethamine. N Engl J Med. 2012;367(26):2461-63.

7. U.S. Government Accountability Office. Drug shortages: FDA's ability to respond should be strengthened. November 2011. Available at: http://www gao.gov/assets/590/587000.pdf. Accessed July 19, 2013.

8. Griffith MM, Pentoney Z, Scheetz MH. Antimicrobial drug shortages: a crisis amidst the epidemic and the need for antimicrobial stewardship efforts to lessen the effects. Pharmacotherapy. 2012;32(8):665-67.

9. McLaughlin MM, Pentoney Z, Scheetz MH. Need for standardization in assessing impact of antibiotic shortages on patient outcomes. Am J Health Syst Pharm. 2012;69(24):2129-30.

10. National Cancer Institute. NCI guidelines for investigators: adverse event reporting requirements for DCTD (CTEP and CIP) and DCP INDs and IDEs. February 29, 2012. Available at: http://ctep.cancer.gov/protocolDevelopment/ electronic_applications/docs/aeguidelines.pdf. Accessed July 19, 2013.

11. Bates DW, Boyle DL, Vander Vliet MB, Schneider J, Leape L. Relationship between medication errors and adverse drug events. J Gen Intern Med. 1995;10(4):199-205.

12. National Coordinating Council for Medication Error Reporting and Prevention. NCC MERP index for categorizing medication errors. 2001. Available at: http://www.nccmerp.org/pdf/indexColor2001-06-12.pdf. Accessed July 19, 2013.

13. CAHPS Hospital Survey. HCAHPS: Hospital care quality information from the consumer perspective. Available at: www.hcahpsonline.org Accessed July 19, 2013.

14. Lopez-Gonzalez E, Herdeiro MT, Figueiras A. Determinants of under-reporting of adverse drug reactions: a systematic review. Drug Saf. 2009;32(1):19-31. 